\title{
Polyether Ether Ketone: The High-Performance Polymer in Dentistry
}

\author{
Lorena Scaioni Silva1, Victor Eduardo de Souza Batista,DDS, MSc, $\mathbf{P h D}^{2 *}$ \\ ${ }^{1}$ Undergraduate in Dentistry, Presidente Prudente Dental School, University of Western São Paulo - \\ UNOESTE, Presidente Prudente, São Paulo, Brazil \\ ${ }^{2}$ Associate Professor, Department Prosthodontics, Presidente Prudente Dental School, University of Western \\ São Paulo - UNOESTE, Presidente Prudente, São Paulo, Brazil \\ *Corresponding Author: Victor Eduardo de Souza Batista, Associate Professor, Department \\ Prosthodontics, Presidente Prudente Dental School, University of Western São Paulo - UNOESTE, \\ Presidente Prudente, São Paulo, Brazil.Email: victor_edsb@hotmail.com
}

\begin{abstract}
The search for a material that presents minor limitations in dentistry has been leading to the need to insert new materials. In this context, a high performance polymer is being investigated and used, the polyether ether ketone (PEEK), which presents promising characteristics as an alternative to titanium dental implants, temporary abutments for dental implant and partial removable prosthesis due to its chemical resistance, mechanical properties, radiolucency, and easily modeled with hand drills or milling cutters.
\end{abstract}

Keywords: Dental Materials, Biocompatible Materials, Dentistry

\section{EDITORIAL}

Polyether ether ketone (PEEK) is a high strength thermoplastic polymer composed of a backbone molecular aromatic chain and interconnected by ketone and ether groups, which it was developed by a group of English scientists in 1978 [1,2]. In the late 1990's, PEEK was implemented in medicine, as a replacement for metal implants in orthopedic applications for fracture fixation and femoral prosthesis in the hip joint, due to its similarity to the bone skeleton $[3,4]$.

With the advancement of dentistry, the search for ideal materials is constant and the PEEK have been showed as a promising material as alternative in oral rehabilitation, due to its biocompatibility, chemical resistance, insolubility, gamma and X-ray resistance, radiolucency, excellent thermal stability (up to $335.8{ }^{\circ} \mathrm{C}$ ) allowing sterilization using steam, gamma and ethylene oxide $[1,4,5,6]$. Studies reported that a flexural modulus of $140-170 \mathrm{MPa}$ and the modulus of elasticity similar to the human bone, enamel and dentin (PEEK: 3-4 $\mathrm{GPa}$ ), thus, showing superiority values when compare to metal alloys and ceramic restorations (materials widely used in restorative dentistry). Furthermore, the PEEK may be machined or easily worn out with hand drills $[7,8]$. However, the PEEK presents some limitations: it requires coating due to low translucency and grayish pigmentation, impacting the aesthetic result. Another limitation of the application of PEEKbased polymers in dental prosthesis is the difficulty of joining the polymer with composite resin materials due to low surface energy and resistance to surface modification by different chemical treatments, the untreated PEEK surface is bioinert hydrophobic and it is not possible to obtain the osseointegration in its pure form $[2,9]$.

Some strategies have been adopted to circumvent these limitations, as to perform the acid conditioning on the PEEK surface, for subsequent coating with composite, enabling its use in aesthetic regions and as substructure material, especially in areas of occlusal loading [10]. Cause it is an inert material, the association of PEEK with hydroxyapatite nanoparticles has been proposed $[9,10,11]$, since its association presented better mechanical properties when compared to the pure material, showing increased activity of fibroblasts $[1,12]$.

The excellent mechanical properties of PEEK have been confirmed in several studies present in the literature, showing that this polymer has greater strength than lithium disilicate ceramic $(950 \mathrm{~N})$, alumina $(851 \mathrm{~N})$ or zirconia $(981-1331$ 
$\mathrm{N})$. The fracture resistance of CAD-CAM milled fixed prostheses in PEEK is 2354N $[2,13,14]$. Randomized controlled clinical trial showed that there is no statistically significant difference between the PEEK pillars compared to titanium and the PEEK did not cause bone resorption or inflammation, showing a promising alternative to titanium support [15]. Regarding the bacterial adhesion, the PEEK showed similar behavior when compared to cp- Ti, and Ti6Al4V [16].

At the moment, there no enough information in the literature about the abrasion of the PEEK with other materials such as metal alloys, ceramics, dentin or enamel in order to simulate the function in mouth. However, PEEK has been used to make dental implants, individual abutments for dental implant, temporary abutments for dental implant [17], removable partial prostheses with staples in aesthetic regions [15], fixed dental prostheses [18], and maxillary obturator prostheses [19].

Finally, the PEEK is a modern material and it has excellent physical, chemical and mechanical properties for use in dentistry; however, future researches and clinical trials are needed to confirm the quality and actual clinical applications of this material in relation to dental procedures, because most of the studies present in literature were performed in vitro.

\section{REFERENCES}

[1] Monich PR, Berti FV, Porto LM, Henriques B, de Oliveira APN, Fredel MC et al. (2017) Physicochemical and biological assessment of PEEK composites embedding natural amorphous silica fi bers for biomedical applications. Materials Science and Engineering 79: 354-62.

[2] Kurtz S.M., Devine J.N (2007) Peek biomaterials in trauma, orthopedic, and spinal implants. Biomaterials 28: 4845-4869.

[3] Pargaonkar SS, Prabhune MS, Patil VV, Deshpande PA Kolhe VN (2015) A Polyaryletherketone biomaterial for use in medical implant applications. International Journal of Scientific and Reserch Publications 5: 44-49.

[4] Ma R, Tang T (2014) Current strategies to improve the bioactivity of PEEK. International journal of molecular sciences 15: 5426-45.

[5] Stawarczyk B, Thrun H, Eichberger M, Roos M, Edelhoff D, Schweigger J (2015) Effect of different surface preteatments and adhesives on the load-beaing capacity of veneered 3-until PEEK FDPs. J Prosthet Dent 114: 666-73.
[6] Xin H, Shepherd D, Dearn K (2013) Strength of poly-etherether-ketone: effects of sterilisation and thermal ageing. Polymer Testing 32: 10011005

[7] Nieminen T., Kallela I., Wuolijoki E., Kainulainen H., Hiidenheimo I., Rantala I (2008) Amorphous and crystalline polyetheretherketone: Mechanical properties and tissue reactions during a 3-year follow-up. J. Biomed. Mater. Res. Part A 84: 377-83.

[8] Williams D (2008) Polyetheretherketone for long-term implantable devices. Med Device Technol 19:8, 10-1.

[9] Rabiei A., Sandukas S (2013) Processing and evaluation of bioactive coatings on polymeric implants. J. Biomed. Mater. Res. Part A.

[10] Ma R, Tang T. Current strategies to improve the bioactivity of PEEK. International Journal of Molecular Sciences. 2014; 15(4): 5426-5445.

[11] Johansson P, Jimbo R, Naito Y, Kjellin P, Currie F, Wennerberg A (2016) Polyether ether ketone implants achieve increased bone fusion when coated with nano-sized hydroxyapatite: a histomorphometric study in rabbit bone. Int $\mathbf{J}$ Nanomedicine 6: 1435-42.

[12] Rikitoku S, Otake S, Nozaki K, Yoshida K, Miura $\mathrm{H}$ (2019) Influence of $\mathrm{SiO}_{2}$ content of polyetheretherketone (PEEK) on flexural properties and tensile bond strength to resin cement. Dent Mater J 38:464-470.

[13] Stawarczyk B, Eichberger M, Uhrenbacher J, Wimmer T, Edelhoff D, Schmidlin PR (2015) Three-unit reinforced polyetheretherketone composite FDPs: Influence of fabrication method on load-bearing capacity and failure types. Dental materials Journal 34: 7-12.

[14] Stawarczyk B, Beuer F, Wimmer T, Jahn D, Sener B, Roos M et al. (2013) Polyetheretherketone - a suitable material for fi xed dental prostheses? Journal of Biomedical Materials Research Part B: Applied Biomaterials 101: 1209-16.

[15] Najeeb S, Zafar MS, Khurshid Z, Siddiqui F (2016) Applications of polyetheretherketone (PEEK) in oral implantology and prosthodontics. Journal of prosthodontic Research 60: 12-9.

[16] Barkarmo S, Longhorn D, Leer K, Johansson CB, Stenport V, Franco-Tabares S, Kuehne SA, Sammons R. (2019) Biofilm formation on polyetheretherketone and titanium surfaces. Clin Exp Dent Res 13;5(4):427-437.

[17] Santing HJ, Meijer HJ, Raghoebar GM, Ozcan M (2012) Fracture strength and failure mode of maxillary implant supported provisional single crowns: A comparison of composite resin crowns fabricated directly over PEEK abutments and solid titanium abutments. Clin Implant Dent Relat Res 14: 882-9. 
[18] Uhrenbacher J, Schmidlin PR, Keul C, Eichberger M, Roos M, Gernet W (2014) The effect of surface modifi cation on the retention strength of polyetheretherketone crowns adhesively bonded to dentin abutments. The Journal of prosthetic dentistry 112: 1489-97.
[19] Costa-Palau S, Torrents-Nicolas J, Brufau-de Barberà M, Cabratosa-Termes J (2014) Use of polyetheretherketone in the fabrication of a maxillary obturator prosthesis: a clinical report. The Journal of prosthetic dentistry 112:680-2.

Citation: Lorena Scaioni Silva, Victor Eduardo de Souza Batista. Polyether Ether Ketone: The HighPerformance Polymer in Dentistry. ARC Journal of Dental science. 2019; 4(4):5-7. doi:dx.doi.org/10.20431/ 2456-0030.0404002.

Copyright: (C) 2019 Authors. This is an open-access article distributed under the terms of the Creative Commons Attribution License, which permits unrestricted use, distribution, and reproduction in any medium, provided the original author and source are credited. 